\title{
UMA ABORDAGEM DE PROJETOS DE ENGENHARIA NA EDUCAÇÃO BÁSICA UTILIZANDO SIMULAÇÃO ON-LINE
}

DOI: 10.37702/2175-957X.COBENGE.2021.3675

Darlan da Silva Anastácio - darlan.anastacio@hotmail.com

Universidade de Pernambuco

Rua Genésio Teófilo Bezerra Filho 40

50690-400 - Recife - PE

Flávia Camila Morais de Oliveira - fcmo@poli.br

Universidade de Pernambuco

Rua Andarai 403

54410-460 - Jaboatão dos Guararapes - PE

Maria de Lourdes Melo Guedes Alcoforado - mlmga@poli.br Universidade de Pernambuco

Rua Setubal 1492

51130-010 - Recife - PE

Resumo: Este documento apresenta uma abordagem para imersão inicial de alunos da educação básica em aplicações de engenharias elétricas, enfatizando a contextualização entre teoria e prática das disciplinas estudadas em sala de aula. Elabora-se um projeto de automação para irrigação de um jardim em uma ferramenta on-line de simulações de circuitos elétricos a fim de estimular o interesse dos alunos a ingressar em cursos de engenharia.

Palavras-chave: Educação básica. Simulação de circuito elétrico. Software on-line. 


\section{UMA ABORDAGEM DE PROJETOS DE ENGENHARIA NA EDUCAÇÃO BÁSICA UTILIZANDO SIMULAÇÃO ON-LINE}

\section{INTRODUÇÃO}

Existe uma preocupação no meio acadêmico com a reprovação e evasão dos discentes nas primeiras etapas da Educação Superior. O despreparo dos alunos ingressantes em engenharias para enfrentar conceitos abordados na graduação está relacionado à formação escolar básica em disciplinas como Matemática e Ciências Naturais, devido à falta de conexões entre os estudos do ciclo básico de aprendizagem e suas aplicações práticas profissionalizantes (GODOY; ALMEIDA, 2017).

Embora existam vários motivos para essa evasão, as principais causas estão vinculadas à metodologia tradicional expositiva de ensino que não prioriza a contextualização dos assuntos ensinados com práticas reais de tecnologias. O que sugere a abordagem do modelo educacional que enfatiza as interconexões entre Ciência, Tecnologia, Engenharias e Matemática (STEM, Science, Technology, Engineering and Mathematics) (CALAZANS; BARROS; ALCOFORADO, 2021).

Essa é uma metodologia onde o aluno tem função ativa, age como sujeito central da sua aprendizagem. Um método ensino ativo traz mais autonomia e responsabilidade para o aluno, que irá interagir mais, discutir e construir o conhecimento, em vez de apenas absorver de forma passiva (FOFANCA et al., 2018).

Diante desse cenário, este trabalho pretende introduzir os alunos do ensino básico na metodologia STEM. Partindo de um conhecimento prévio de ciências e tecnologias, mostrase a relação deles com conteúdos de Matemática, Física e Biologia. Pretende-se que, com essa interdisciplinaridade, o aluno tenha noções do que esperar em cursos de engenharia, sendo um estímulo inicial ao interesse de jovens para essas áreas. Para tanto, utiliza-se uma ferramenta de simulação de circuitos elétricos com um projeto de automação para irrigação de um jardim.

\section{METODOLOGIA ADOTADA}

Nesta proposta educacional, utiliza-se uma aplicação Tinkercad (2021), que é uma coleção on-line gratuita de ferramentas que introduz pessoas em softwares de design 3D, entretenimento 3D e em softwares de simulação de circuitos eletrônicos e de automação.

O desenvolvimento desse circuito serve para auxiliar na administração da irrigação de plantas específicas, pois cada espécie apresenta seu ambiente mais adaptado para cultivo. Isto determina os cuidados de jardinagem que devem ser adotados em cada caso: incidência solar direta ou moderada (quantidade de luz), frequência de irrigação para garantir um solo com umidade adequada (quantidade de água), clima frio ou quente, dentre outras variáveis (MAROUELLI; SILVA; DA SILVA, 2008).

O projeto consiste na concepção de um circuito eletrônico com sensores para regar um jardim de forma automática, utilizando três sensores: sensor de chuva, sensor de umidade do solo e sensor de temperatura. Baseado nas informações dos sensores, o circuito irá liberar a água para irrigar o jardim somente quando for necessário.

A simulação feita no Tinkercad é possível considerando cada um desses sensores como sendo um potenciômetro para garantir o funcionamento do circuito como se tivessem 
leituras de valores em uma determinada escala sendo fornecidos nos pinos de entrada de uma placa de Arduino (MCROBERTS, 2018).

Os elementos que compõem essa simulação computacional são: os sensores de chuva, umidade do solo e temperatura (representados por potenciômetros), uma placa de Arduino UNO, uma matriz de contato (protoboard) para conexão dos componentes eletrônicos (sensores, resistências, LEDs, potenciômetros, por exemplo), fonte de alimentação elétrica de $12 \mathrm{Vcc}$, uma válvula solenoide de $12 \mathrm{Vcc}$ (representada por um LED) e um relé para acoplar a placa de Arduino (comumente funcionando com tensão de $5 \mathrm{~V}$ ) à válvula solenoide.

A Tabela 1 descreve os componentes reais necessários para montar o circuito simulado, bem como os que foram utilizados na simulação, tendo em vista que a plataforma de simulação do Tinkercad não possui exatamente cada modelo sugerido para montagem do circuito real. Por isso, os sensores são simulados por potenciômetros, a fonte de tensão é simulada por uma associação de baterias e a válvula solenoide é simulada por um LED, de tal forma que enquanto o LED estiver aceso significa que a válvula solenoide foi liberada para irrigar. O relé utilizado no Tinkercad é o modelo LU-5-R, como mostra a Figura 2.

Tabela 1 - Lista de componentes do circuito

\begin{tabular}{|c|c|c|}
\hline Componente & Componente Real & $\begin{array}{c}\text { Componente Utilizado na } \\
\text { Simulação }\end{array}$ \\
\hline Placa de Arduino & Arduino UNO & Arduino UNO R3 \\
\hline Sensor de Chuva & FC-37 & Potenciômetro 250k $\Omega$ \\
\hline Sensor de Umidade do Solo & HL-69 & Potenciômetro 250k $\Omega$ \\
\hline Sensor de Temperatura & LM35 (encapsulamento TO-92) & Potenciômetro 250k $\Omega$ \\
\hline Fonte de Alimentação & 12 VcC & Associação de Baterias de 9V \\
\hline Válvula Solenoide & 12 Vcc 3/4" & LED Azul \\
\hline Relé & SONGLE SRD-05VDC-SL-C & LU-5-R \\
\hline
\end{tabular}

Fonte: Autoria própria

Figura 2 - Simulação no Tinkercad 


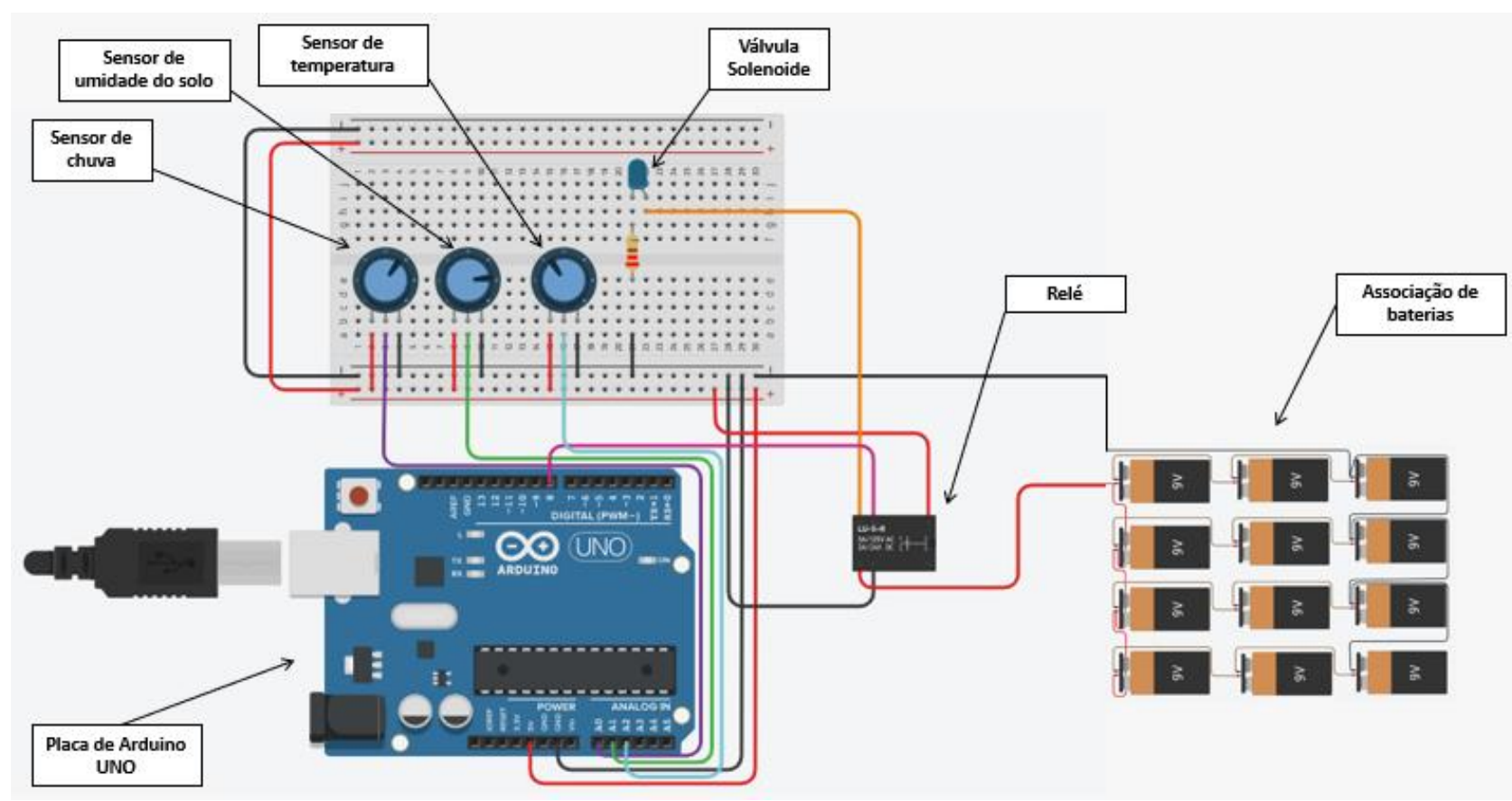

Fonte: Autoria própria

Os ajustes na programação do circuito são feitos na plataforma do Tinkercad em um ambiente de programação gráfica onde existem estruturas de programação com formatos geométricos que se encaixam para garantir a ordem dos blocos de programação e, com isso, garantir a sequência lógica da programação. A Figura 3 exemplifica essa programação, onde pode-se notar a estrutura "se...então" em laranja; os comandos em azul; e as condições necessárias em verde, isto é, $C \leq 63 e 0<U \leq 16$ e $T \leq 61$.

Figura 3 - Simulação no Tinkercad.

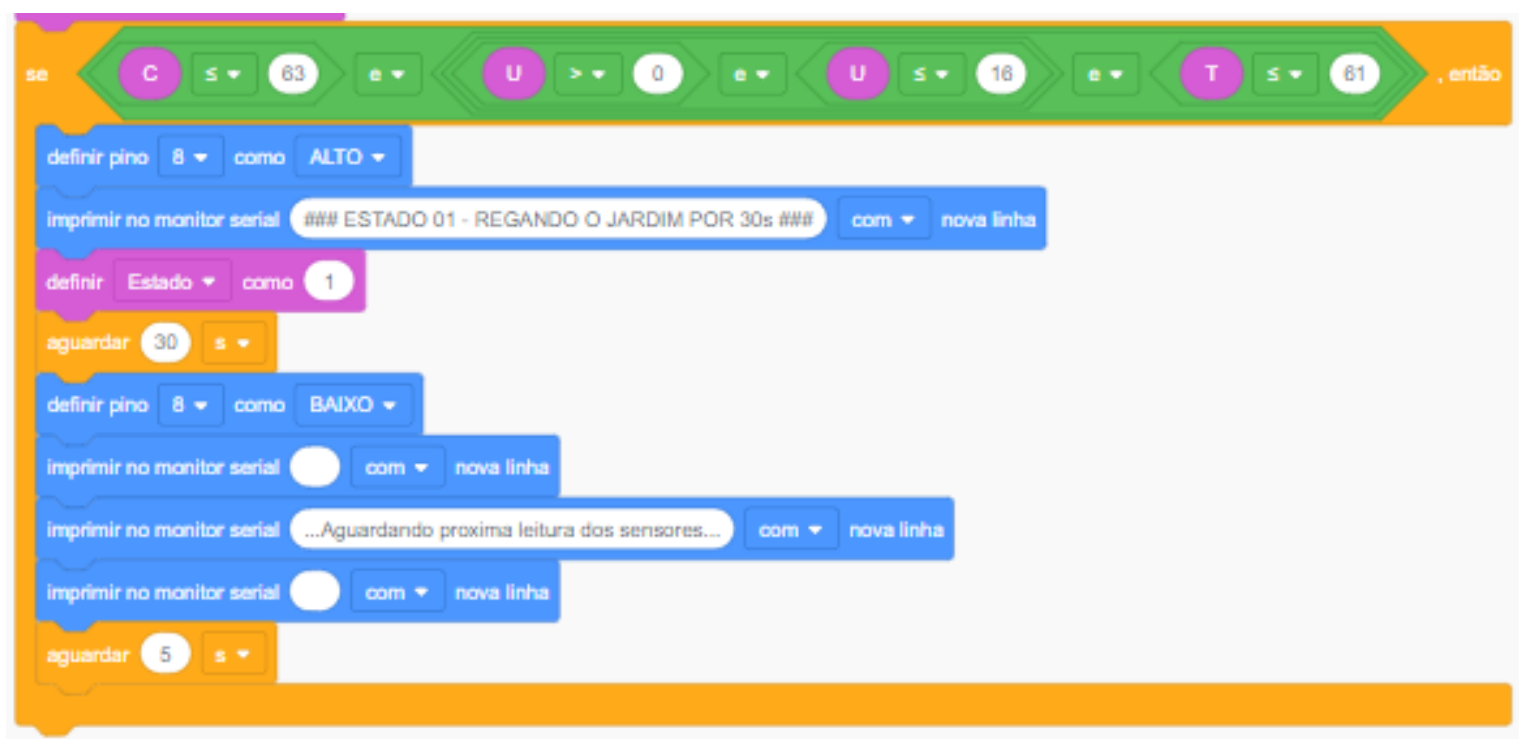

Fonte: Autoria própria 


\section{CIRCUITO A SER SIMULADO NA PLATAFORMA TINKERCAD}

A simulação do circuito é realizada de acordo com o esquema apresentado na Figura 1. Os sensores utilizados são apropriados para conexão direta nas entradas analógicas do Arduino conforme Figuras 4, 5 e 6.

Figura 1 - Esquema de ligações do circuito de irrigação automática.

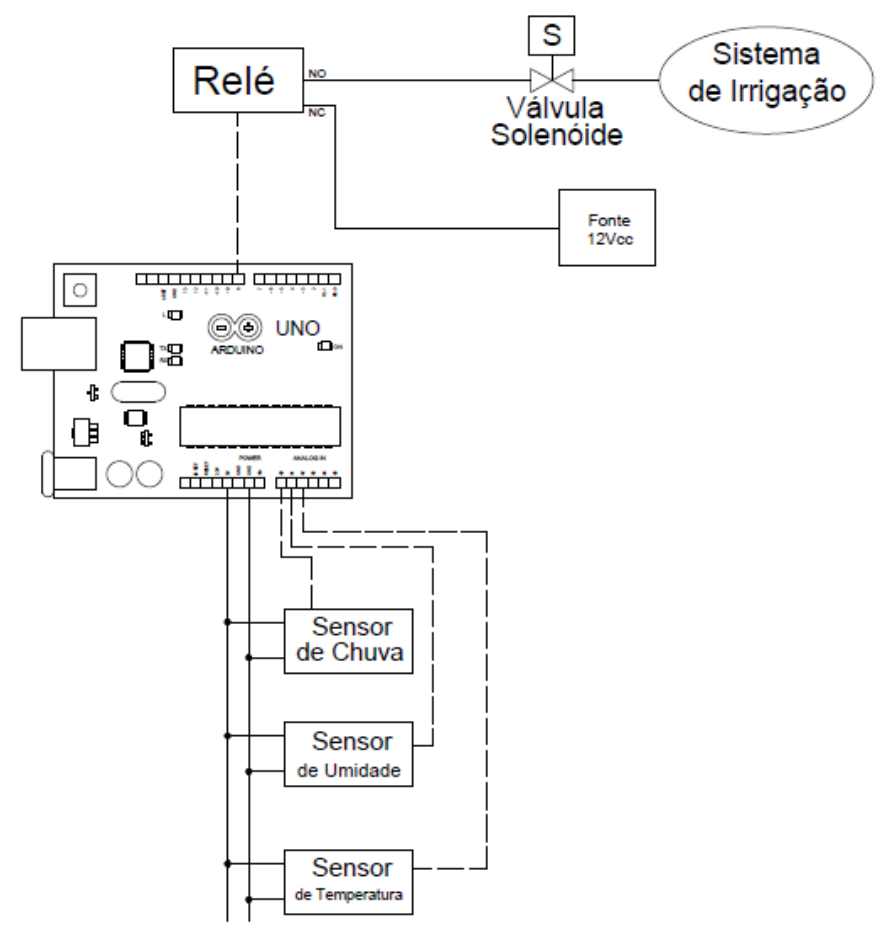

Fonte: Autoria própria

Figura 4 - Conexão do sensor de chuva FC-37

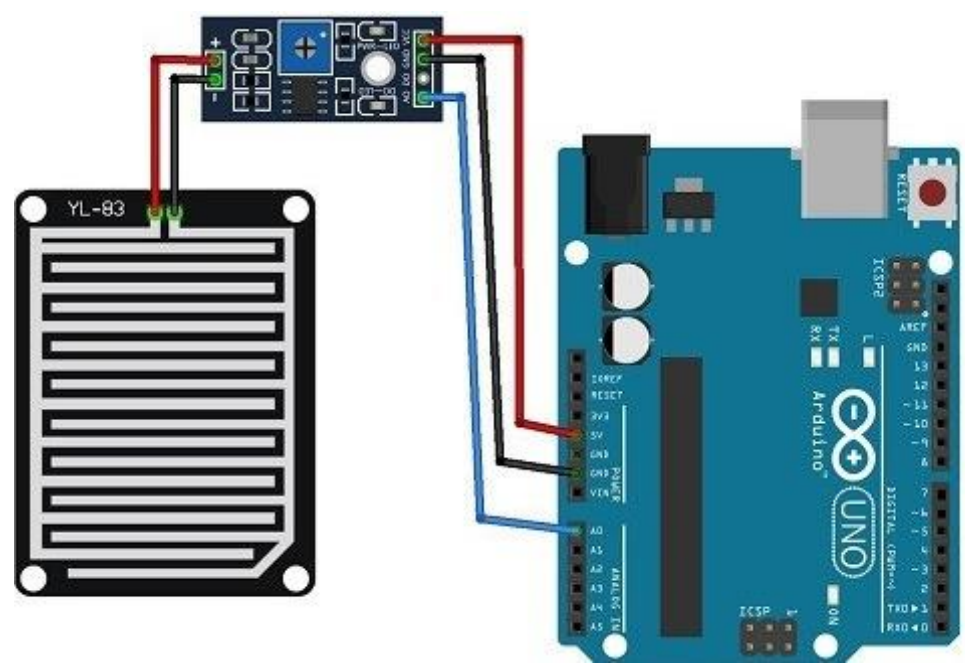

Fonte: Módulo sensor de chuva YL-83 - Renan Martins 2018 https://ardudino.wordpress.com/2018/01/23/modulo-sensor-de-chuva-yl-83/ 
Figura 5 - Sensor de umidade do solo HL-69.

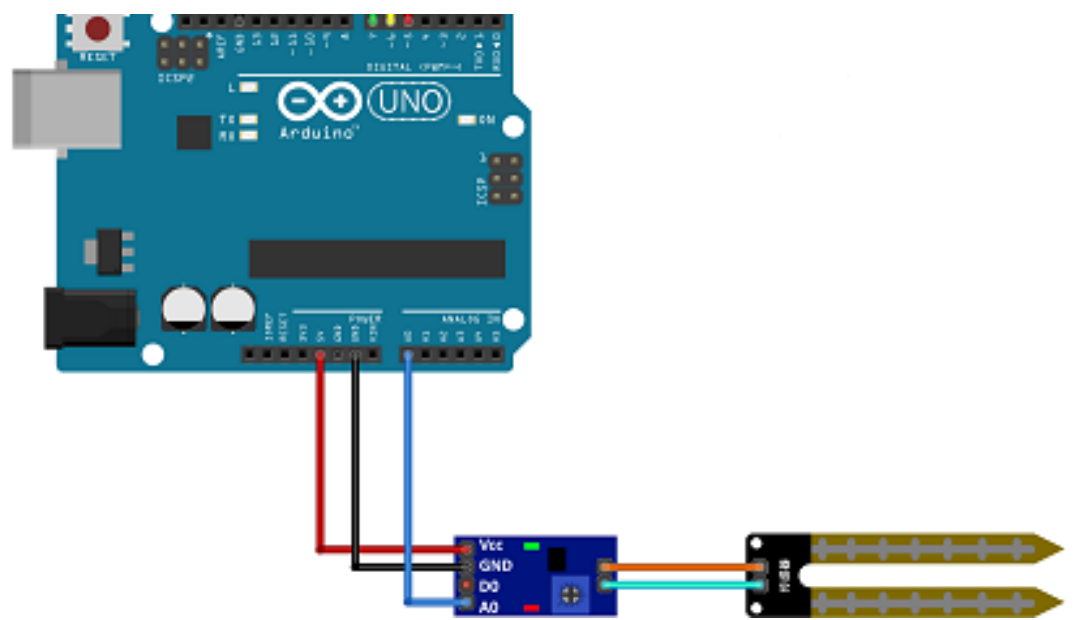

Fonte: Monitore sua planta usando Arduino - Adilson Thomsen 2016 https://www.filipeflop.com/blog/monitore-sua-planta-usando-arduino/

Figura 6 - Sensor de temperatura LM35.

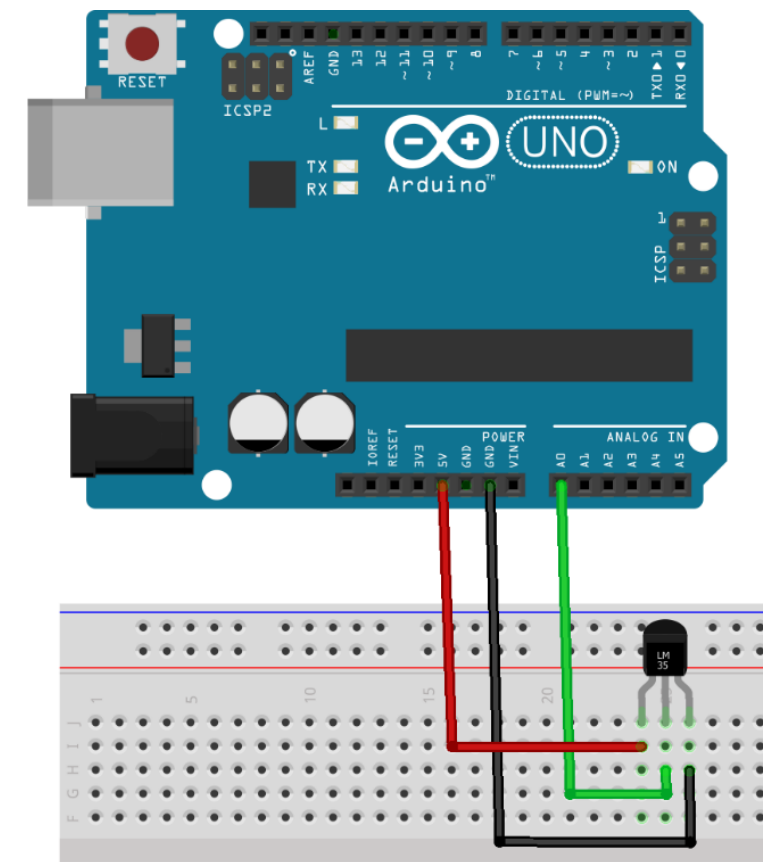

Fonte: Termômetro com Arduíno e sensor LM35 - Nerd King 2016 -

https://nerdking.net.br/termometro-com-arduino-e-sensor-Im35/

A válvula solenoide $12 \mathrm{Vcc} 3 / 4 "$ necessita da conexão de um relé para acoplar o circuito interno do Arduino com tensões típicas de circuitos eletrônicos digitais $5 \mathrm{~V}$ com a fonte de alimentação de $12 \mathrm{Vcc}$. Para isso, é sugerido o modelo SONGLE SRD-05VDC-SL-C (SPDT $5 \mathrm{~V})$, como ilustrado na Figura 7. 
Figura 7 - Conexões da válvula solenoide à placa do Arduino através do Relé.

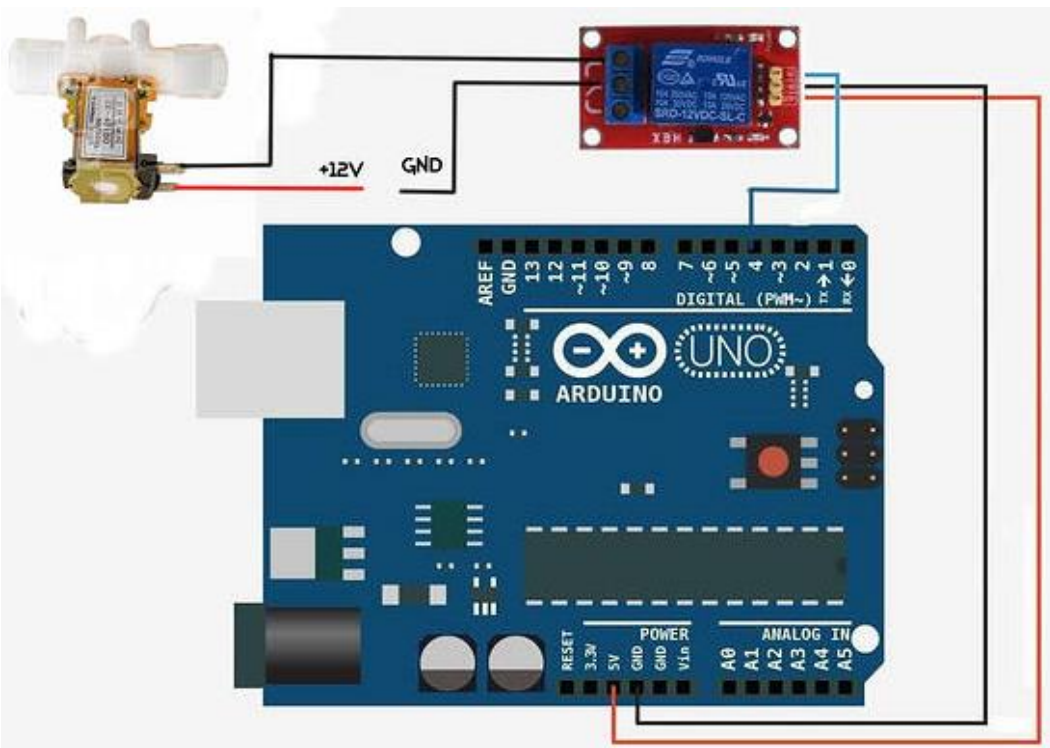

Fontes: Como conectar elevtrovalvula $12 v$ dc - https://forum.arduino.cc/t/como-conectar-elevtrovalvula-12vdc/538937/4.

\section{APRESENTAÇÃO DO CIRCUITO ÀS TURMAS DO ENSINO BÁSICO}

A proposta foi exposta a quatro turmas do ensino básico (nono ano e ensino médio: primeiro, segundo e terceiro anos) por meio de videoconferências e programações on-line. Foram agendados três encontros com cada turma: um primeiro encontro para apresentação do projeto; o segundo encontro para explicações sobre a montagem e funcionamento do circuito e o último encontro para analisar e ajustar a programação na simulação, explorando a estrutura de blocos no Tinkercad.

As informações dos sensores nos pinos analógicos do Arduino, o qual os interpreta como valores em uma escala de 0 a 1023 , a qual é alterada na programação, por conveniência, para uma escala de 0 a 100 e classificada em alguns subintervalos para refletir em detalhe a situação em que se encontram as condições do ambiente no momento das leituras dos sensores, conforme Tabela 2. Essas leituras são feitas periodicamente com intervalo de tempo determinado na programação. Por exemplo, a cada seis horas pode ser feita uma rotina de verificar todos os sensores e identificar se é necessário ou não irrigar o jardim.

Tabela 2 - Classificação das leituras dos sensores.

\begin{tabular}{|c|c|}
\hline Sensor & Classificação das leituras \\
\hline \multirow{3}{*}{ Sensor de Chuva } & Sem Chuva \\
\cline { 2 - 2 } & Chuvisco \\
\cline { 2 - 2 } & Chuva Normal \\
\cline { 2 - 2 } Sensor de Umidade do & Tempestade \\
\cline { 2 - 2 } Solo & Muito Seco \\
\cline { 2 - 2 } & Seco \\
\cline { 2 - 2 } & Úmido \\
\hline
\end{tabular}




\begin{tabular}{|l|c|}
\hline & Encharcado \\
\hline \multirow{2}{*}{ Sensor de Temperatura } & Clima Frio \\
\cline { 2 - 2 } & Clima Quente \\
\hline
\end{tabular}

Fonte: Autoria própria

Nos encontros, os alunos foram agentes ativos na elaboração do funcionamento do projeto, definindo os subintervalos das leituras dos sensores, sugerindo a ação que o circuito iria executar em cada uma das situações possíveis para regar o jardim e por quanto tempo seria realizada essa irrigação em cada caso. Também foi feita uma analogia a partir do cenário montado em conjunto com os alunos em relação a modelos reais que representam monitoramento em plantas adaptadas a condições específicas de acordo com os ajustes propostos em cada turma de aluno. Como exemplo, uma turma propôs intervalos de valores para os sensores e comandos para irrigar o jardim que melhor se enquadram em monitoramento de plantas adaptadas a climas frios e solos secos, com pouca umidade, enquanto para outra turma, a situação refletiu melhor uma planta de clima quente e solo úmido. Na Figura 8 são apresentados os parâmetros escolhidos por cada turma, o tipo de solo e clima correspondente e um exemplo de planta que se adapta a tais condições.

Figura 8 - Definições dos parâmetros nos intervalos de leituras dos sensores.

\begin{tabular}{|c|c|c|c|}
\hline Nono Ano & Primeiro Ano & Segundo Ano & Terceiro Ano \\
\hline${ }^{*}$ Sensor de Chuva & ${ }^{*}$ Sensor de Chuva & ${ }^{*}$ Sensor de Chuva & *Sensor de Chuva \\
\hline Sem Chuva: 0 a 15 & Sem Chuva: 0 a 60 & Sem Chuva: 0 a 30 & Sem Chuva: 0 a 63 \\
\hline Chuvisco: 15 a 30 & Chuvisco: 60 a 75 & Chuvisco: 30 a 50 & Chuvisco: 63 a 71 \\
\hline Chuva Normal: 30 a 60 & Chuva Normal: 75 a 85 & Chuva Normal: 50 a 70 & Chuva Normal: 71 a 86 \\
\hline Tempestade: 60 a 100 & Tempestade: 85 a 100 & Tempestade: 70 a 100 & Tempestade: 86 a 100 \\
\hline * Sensor de Umidade & ${ }^{*}$ Sensor de Umidade & * Sensor de Umidade & * Sensor de Umidade \\
\hline Muito Seco: 0 a 20 & Muito Seco: 0 a 20 & Muito Seco: 0 a 15 & Muito Seco: 0 a 16 \\
\hline Seco: 20 a 30 & Seco: 20 a 40 & Seco: 15 a 30 & Seco: 16 a 38 \\
\hline Úmido: 30 a 50 & Úmido: 40 a 65 & Úmido: 30 a 50 & Úmido: 38 a 51 \\
\hline Encharcado: 50 a 100 & Encharcado: 65 a 100 & Encharcado: 50 a 100 & Encharcado: 51 a 100 \\
\hline${ }^{*}$ Temperatura & *Temperatura & *Temperatura & *Temperatura \\
\hline Clima Frio: 0 a 30 & Clima Frio: 0 a 60 & Clima Frio: 0 a 35 & Clima Frio: 0 a 61 \\
\hline Clima Quente: 30 a 100 & Clima Quente: 60 a 100 & Clima Quente: 35 a 100 & Clima Quente: 61 a 100 \\
\hline SOLO SECO + CLIMA QUENTE & SOLO ÚMIDO + CLIMA FRIO & SOLO ÚMIDO + CLIMA QUENTE & SOLO SECO + CLIMA FRIO \\
\hline Gailárdia & Copo de Leite & Lírio da Paz & Azaleia \\
\hline
\end{tabular}

Fonte: Autoria própria

Foram propostas algumas atividades, como a elaboração de uma planilha com todas as possibilidades de combinações das leituras dos sensores após as definições dos subintervalos acima. Nesta oportunidade, foi abordado o conceito matemático do princípio multiplicativo e, ao definir os subintervalos, foi apresentada a ideia de grandezas físicas contínuas no tempo e grandezas discretas, mostrando como a placa do Arduino recebe de forma digital nas portas de entrada analógica a informação dos sensores de chuva, temperatura e umidade do solo, conforme Figura 9.

Outras interconexões entre teoria das disciplinas do ensino básico e a vida prática profissional foram estimuladas em várias frentes, tais como Biologia (estudo dos solos, cultivo de plantas, estudo do clima, a importância da irrigação para as plantas e sua relação com a fotossíntese e evaporação de água nas folhas) e Física (estudo da vazão de água 
em mangueiras de irrigação, estudo de associações de capacitores ao apresentar a associação das baterias de 9V utilizada na simulação devido à ausência de uma bateria de $12 \mathrm{~V}$ no Tinkercad).

Alguns questionamentos surgiram por parte dos alunos em relação ao funcionamento dos sensores e às definições da programação do circuito de automação. Após discutir a teoria envolvida, ficou evidente que cada sensor funciona basicamente como consequência de aplicação prática de conceitos científicos básicos, por exemplo, a noção de tensão elétrica da Física. Uma das indagações, foi o motivo pelo qual deve-se prever todos os possíveis cenários em que as condições ambientais podem se enquadrar a partir das leituras dos sensores. Para tal curiosidade foi esclarecido que pode ocorrer mudanças repentinas não observadas na rotina de leitura por causa do intervalo de tempo entre uma leitura e outra, de qualquer forma uma programação robusta prevê todos os possíveis cenários das variáveis físicas envolvidas.

Figura 9 - Planilha com combinações dos subintervalos.

\begin{tabular}{|c|c|}
\hline Cenário & (Chuva) + (Umidade) + (Temperatura) \\
\hline 01 & Sem Chuva + Muito Seco + Clima Frio \\
\hline 02 & Sem Chuva + Muito Seco + Clima Quente \\
\hline 03 & Sem Chuva + Seco + Clima Frio \\
\hline 04 & Sem Chuva + Seco + Clima Quente \\
\hline 05 & Sem Chuva + Úmido + Clima Frio \\
\hline 06 & Sem Chuva + Úmido + Clima Quente \\
\hline 07 & Sem Chuva + Encharcado + Clima Frio \\
\hline 08 & Sem Chuva + Encharcado + Clima Quente \\
\hline 09 & Chuvisco + Muito Seco + Clima Frio \\
\hline 10 & Chuvisco + Muito Seco + Clima Quente \\
\hline 11 & Chuvisco + Seco + Clima Frio \\
\hline 12 & Chuvisco + Seco + Clima Quente \\
\hline 13 & Chuvisco + Úmido + Clima Frio \\
\hline 14 & Chuvisco + Úmido + Clima Quente \\
\hline 15 & Chuvisco + Encharcado + Clima Frio \\
\hline 16 & Chuvisco + Encharcado + Clima Quente \\
\hline 17 & Chuva Normal + Muito Seco + Clima Frio \\
\hline 18 & Chuva Normal + Muito Seco + Clima Quente \\
\hline 19 & Chuva Normal + Seco + Clima Frio \\
\hline 20 & Chuva Normal + Seco + Clima Quente \\
\hline 21 & Chuva Normal + Úmido + Clima Frio \\
\hline 22 & Chuva Normal + Úmido + Clima Quente \\
\hline 23 & Chuva Normal + Encharcado + Clima Frio \\
\hline 24 & Chuva Normal + Encharcado + Clima Quente \\
\hline 25 & Tempestade + Muito Seco + Clima Frio \\
\hline 26 & Tempestade + Muito Seco + Clima Quente \\
\hline 27 & Tempestade + Seco + Clima Frio \\
\hline 28 & Tempestade + Seco + Clima Quente \\
\hline 29 & Tempestade + Úmido + Clima Frio \\
\hline 30 & Tempestade + Úmido + Clima Quente \\
\hline 31 & Tempestade + Encharcado + Clima Frio \\
\hline 32 & Tempestade + Encharcado + Clima Quente \\
\hline
\end{tabular}

Fonte: Autoria própria 
A abordagem e a linguagem utilizada ao apresentar os conceitos teóricos e suas relações com a prática foram exploradas com aprofundamento diferenciado para cada turma, tentando refletir o nível de série no Estudo Básico e garantir o entendimento e entrosamento de cada turma. Entretanto, a experiência com a turma do nono ano não pôde ser concluída devido a alguns fatores: a falta de recursos que pudessem despertar mais seu interesse por se tratar de uma turma de alunos mais jovens, por exemplo a presença de um circuito real com os componentes e sensores conectados; o formato de apresentação em videoconferência não pareceu ser muito atrativo para esta faixa etária. Talvez fosse mais interessante realizar encontros presenciais com essa turma devido à faixa etária.

\section{RESULTADOS}

Após a realização dos encontros com as turmas do ensino básico, foi feita uma pesquisa para medir a motivação dos alunos em projetos semelhantes, os resultados são apresentados por meio dos gráficos abaixo. Observa-se que $71,4 \%$ julgaram o tempo dos encontros adequado. Analisando o segundo gráfico, nota-se que $14,3 \%$ dos alunos ficaram interessados no projeto e $42,9 \%$ responderam que talvez se engaje depois, mostrando que o interesse da maioria dos alunos foi despertado para a área de engenharia a partir da apresentação do projeto. Essa percepção também pôde ser observada durante os encontros, com a participação dos alunos, inclusive, um dos alunos sugeriu na pesquisa um projeto com essa abordagem STEM utilizando montagem de circuito com painel solar.

Figura 10 (a) - Pesquisa de motivação.

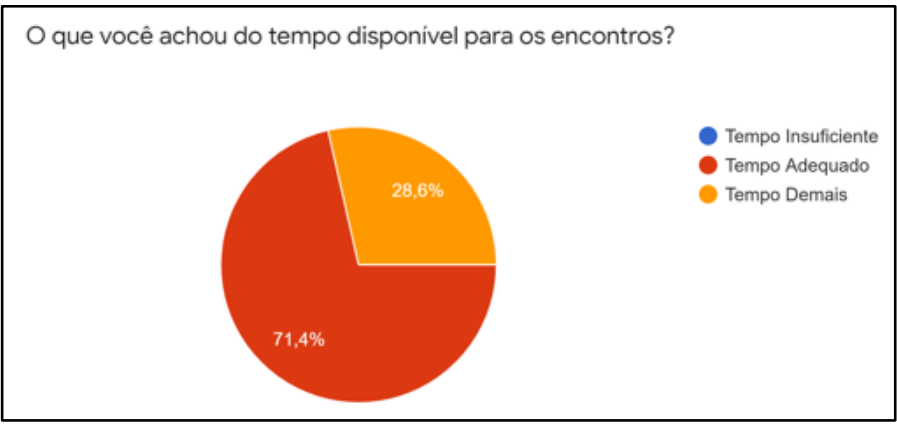

Fonte: Autoria própria

Figura 10 (b) - Pesquisa de motivação.

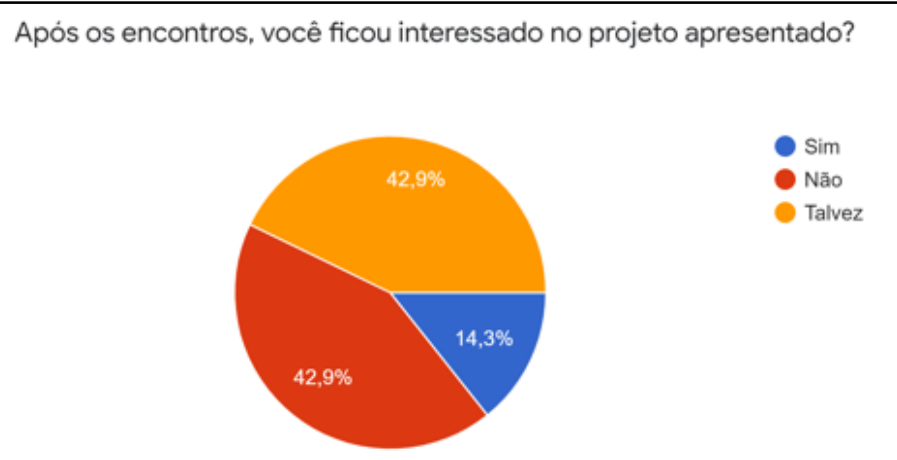

Fonte: Autoria própria 


\section{CONCLUSÕES}

Nesse contexto, fica evidente a importância de apresentações de tecnologias de forma que proporcione uma imersão inicial do estudante da Educação Básica em tópicos importantes em engenharias, mostrando o elo entre a teoria da sala de aula e a prática de projetos.

Posteriormente a este trabalho, como planejamento futuro, poderá ser feita a aquisição de placas Arduino e módulos (Shields) com sensores para montar os circuitos reais e verificar o funcionamento presencialmente com os alunos na instituição de ensino. Além disso, pode-se desenvolver projetos semelhantes utilizando esta abordagem para despertar o interesse de alunos do ensino básico para ingressar em cursos de engenharias, como o exemplo sugerido em um dos encontros para desenvolver um projeto de conversão de energia solar em energia elétrica utilizando placas fotovoltaicas.

\section{Agradecimentos}

Os autores gostariam de expressar os seus sinceros agradecimentos à Coordenação de Aperfeiçoamento de Pessoal de Nível Superior (CAPES).

\section{REFERÊNCIAS}

AUTODESKC TINKERCAD, Da Mente ao Projeto em Minutos. Disponível em: https://www.tinkercad.com. Acesso em: 25 de abr. 2021.

CALAZANS, M.A.A.C.; BARROS, F.C.P.; ALCOFORADO, M.L.M.G., UMA ABORDAGEM DE METODOLOGIA STEM EM CÓDIGOS CORRETORES DE ERROS, HIPERTEXTUS REVISTA DIGITAL.

Disponível

em:

https://periodicos.ufpe.br/revistas/hipertextus/search/authors/view?firstName=Francisco\& middleName=Caio\%20Parente\%20de\&lastName=Barros\&affiliation=\&country=BR.

Acesso em: 25 de abr. 2021.

Como conectar elevtrovalvula 12v dc. 2018. Disponível em: https://forum.arduino.cc/t/como-conectar-elevtrovalvula-12v-dc/538937/4. Acesso em 26 de abr. 2021.

FOFANCA, E. et al. METODOLOGIAS PEDAGÓGICAS INOVADORAS, Volume 2, Editora IFPR, 2018. Disponível em: https://reitoria.ifpr.edu.br/wp-content/uploads/2018/08/E-bookMetodologias-Pedagogicas-Inovadoras-V.2 Editora-IFPR-2018.pdf. Acesso em: 27 de abr. 2021.

GODOY, E.V.; ALMEIDA, E., A evasão nos cursos de Engenharia e a sua relação com a Matemática: uma análise a partir do COBENGE, Educação Matemática Debate, Montes Claros, v. 1, n. 3, set./dez. 2017. Páginas 343-344. Disponível em: http://dx.doi.org/10.24116/emd25266136v1n32017a05. Acesso em: 25 de abr. 2021.

MAROUELLI, W.A.; SILVA, W.L.C.; DA SILVA, H.R. Irrigação por aspersão em hortaliças: qualidade da água, aspectos do sistema e método prático de manejo. Brasília, DF: Embrapa Informação Tecnológica, 2008. 
MARTINS, R. Módulo sensor de chuva YL-83. 2018 Disponível em: https://ardudino.wordpress.com/2018/01/23/modulo-sensor-de-chuva-yl-83/. Acesso em 25 de abr. 2021.

MCROBERTS, M. Arduino básico. Novatec Editora, 2018.

SONGLE RELAY. RELAY ISO9002. Disponível em: https://components101.com/asset/sites/default/files/component datasheet/5V\%20Relay\% 20Datasheet.pdf. Acesso em 26 de abr. 2021.

Termômetro com Arduíno e sensor LM35. Nerd King 2016. Disponível em: https://nerdking.net.br/termometro-com-arduino-e-sensor-Im35/. Acesso em 25 de abr. 2021.

THOMSEN, A. Monitore sua planta usando Arduino. FLIPEFLOP, 2016. Disponível em: https://www.filipeflop.com/blog/monitore-sua-planta-usando-arduino/. Acesso em 25 de abr. 2021.

\section{AN APPROACH TO ENGINEERING PROJECTS IN BASIC EDUCATION USING ONLINE SIMULATION}

Abstract: This document presents an approach for the initial immersion of basic education students in electrical engineering applications, emphasizing the contextualization between theory and practice of the subjects studied in the classroom. An automation project for the irrigation of a garden is elaborated using an online tool for simulating electrical circuits in order to stimulate students' interest in entering engineering courses.

Keywords: Basic education. Electrical circuit simulation. Software online. 